\title{
A Study on Premenstrual Syndrome symptoms and their association with the Attitudes towards Menstruation in Nursing Staff
}

\author{
Hiba Narvel ${ }^{1}$, Heena Merchant ${ }^{2}$, Gauri Kore ${ }^{3}$, Ajita Nayak ${ }^{4}$, Avinash De Sousa ${ }^{5}$ \\ ${ }^{1} 9^{\text {th }}$ Semester Medical Student, Seth G.S. Medical College and K.E.M. Hospital, Mumbai. \\ ${ }^{2}$ Associate Professor, Department of Psychiatry, Lokmanya Tilak Municipal Medical College and General \\ Hospital Mumbai, \\ $3^{3} 9^{\text {th }}$ Semester Medical Student, Seth G.S. Medical College and K.E.M. Hospital, Mumbai. \\ ${ }^{4}$ Professor, Department of Psychiatry, Seth G.S. Medical College and K.E.M. Hospital, Mumbai. \\ ${ }^{5}$ Research Associate, Department of Psychiatry, Lokmanya Tilak Municipal Medical College and General \\ Hospital, Mumbai.
}

Corresponding author: Heena Merchant

Email - heenathedoc@gmail.com

\begin{abstract}
Background: Symptoms in the premenstrual period have a detrimental impact on the general health of women. There is a lack of studies examining the relationship between menstrual attitudes and symptoms of premenstrual syndrome (PMS), especially in the Indian scenario. This study was conducted to look at contributing factors, frequency of PMS in different age groups and the association of these symptoms towards the attitude towards menstruation in nursing staff.

Methodology: The cross-sectional study involved 450 female nursing staff between 25-50 years of age from various tertiary care hospitals who were administered the Premenstrual Tension Syndrome Rating Scale (PMTS) and Menstrual Attitude Questionnaire (MAQ). The data was then statistically analyzed.

Results: The prevalence of premenstrual symptoms was found to be $85.6 \%$ amongst the participants (according to the ACOG criteria), while the proportion of females suffering from PMS (according to DSM IVTR criteria) was $36.5 \%$. On studying the association, a negatively significant correlation between scores on PMTS and mean scores of MAQ across all age groups.

Conclusion: The intensity of PMS was associated with negative menstrual attitude in our study. Further studies on PMS, its frequent symptoms and relevant variables may guide psychoeducational interventions and need to carried out in larger and diverse populations to corroborate our findings.
\end{abstract}

Key words: premenstrual symptoms, menstrual attitude, Premenstrual Tension Syndrome Rating Scale (PMTS), Menstrual Attitude Questionnaire (MAQ).

(Paper received $-9^{\text {th }}$ October 2018, Peer review completed $-20^{\text {th }}$ November 2018)

(Accepted $-24^{\text {th }}$ November 2018)

\section{INTRODUCTION}

Menstruation is a physiological process related to multiple psychosocial elements with varied attitudes being prevalent about the same [1]. Premenstrual syndrome (PMS) is a condition that describes the physical, cognitive, affective, and behavioural symptoms that may occur cyclically during the luteal phase of the menstrual cycle (a week prior to the onset of menstruation) and resolves within days of onset of menstruation 
[2-4]. PMS affects a major proportion of women and impairs physical, mental and social health [5], leads to loss of work days [6], affects sleep quality [7], disrupts family relations [8], reduces academic achievement and affects quality of life and productivity [9].

It has been hypothesized that attitudes of women towards menstruation may affect the number of symptoms of PMS experienced by the women and their severity [10]. Multiple theories have evolved regarding the etiology and pathophysiology of PMS and it is a common belief that hormonal, genetic, psychosocial, and lifestyle factors may impact the development of PMS [11-12]. Factors such as cultural background [13], educational status [14] and menstrual problems like dysmenorrhea also affect PMS [15]. PMS is condition to which more than 200 varied symptoms have been reported [16]. Some of the common symptoms reported in PMS include depression, anxiety, fatigue, irritability, anger and aggressive outbursts, crying spells, decreased concentration, confusion, headaches, joint pains, abdominal pain, edema, weight gain, changes in libido and appetite, gastrointestinal symptoms, breast tenderness and sleep problems like insomnia and hypersomnia [17].

There is a dearth of Indian literature on PMS and its correlation with attitudes towards menstruation. The current study aimed to analyse frequency and prevalence of PMS symptoms among nursing staff belonging to different age groups study its association to the attitude towards menstruation.

\section{METHODOLOGY}

This was a cross-sectional study conducted in nursing staff aged 25-50 years and working in two tertiary general hospitals i.e. K.E.M. Hospital and Lokmanya Tilak Municipal General Hospital, Mumbai. Institutional ethics committee was obtained for the study. Nursing staff were approached directly to obtain information for the same and one on one interviews were conducted. Written and valid informed consent was taken prior to the study. The inclusion criteria were nursing staff between the age of 20-50 years that were having a regular menstrual cycle. Nursing staff on hormonal therapy and oral contraceptives were excluded from the study. Nursing staff which major gynecological problems that would affect menstruation were also excluded from the study. The minimum optimum sample size obtained by using appropriate statistical formula resulted to be 440. As the total number of nurses in K.E.M. Hospital was found to be twice of that in the other centre, we decided on 450 as a sample size with 300 nurses from K.E.M. Hospital and 150 from Lokmanya Tilak Municipal General Hospital.

The questionnaires used for the study were -

1. Premenstrual Tension Syndrome Observer Rating Scale (PMTS): The scale includes 11 domains with a total maximum score of 40 . It has a reliability coefficient 0.97 and has been widely used in studies on PMS [17].

2. Menstrual Attitude Questionnaire (MAQ): This is a scale to measure menstrual attitudes and perceptions of menstrual and premenstrual distress across cultures. The inter-rater concordance was found to be $98 \%$. The questionnaire had 22 items [18].

Both the scales were administered in a single setting to the participants.

\section{STATISTICAL ANALYSIS}

Descriptive statistics with frequency and percentage representing categorical variables were used while mean and standard deviation was used for the continuous variables. The comparison of continuous variables was done using Spearman Rank Correlation or nominal scale Chi square test. The statistical analysis was doing using a software (Statistical Package for Social Sciences, version SPSS20 software).

\section{RESULTS}

The subjects were 450 nursing staff from both the centres which has in fact a total of 1130 nursing staff. We wanted an equal sample size from different age groups. Hence, we interviewed 150 nursing staff each from three age groups viz. 25-35 years, 35-45 years and $>45$ years across both centres. On assessing socio- 


\begin{tabular}{|c|c|c|c|c|c|c|c|}
\hline \multirow{2}{*}{ Variables } & Age & \multicolumn{2}{|c|}{$\mathbf{2 5 - 3 5}$ years } & \multicolumn{2}{c|}{ 35-45 years } & \multicolumn{2}{c|}{$>$ 45 years } \\
\cline { 2 - 8 } & Range & Mean & SD & Mean & SD & Mean & SD \\
\hline Total score of PMTS & $0-40$ & 10.67 & 4.67 & 17.6 & 6.46 & 10.67 & 4.01 \\
& & & & & & & \\
\hline Depressed mood & $0-4$ & 1.08 & 0.82 & 1.2 & 0.94 & 1.03 & 0.8 \\
\hline Anxiety/Tension & $0-4$ & 0.79 & 0.85 & 1.2 & 0.93 & 0.95 & 0.76 \\
\hline Affective lability & $0-4$ & 1.39 & 0.78 & 1.27 & 1.00 & 0.99 & 0.74 \\
\hline Irritability & $0-4$ & 1.35 & 0.82 & 1.28 & 0.95 & 1.01 & 0.77 \\
\hline Decreased Interest & $0-4$ & 1.02 & 0.83 & 1.8 & 0.99 & 0.86 & 0.72 \\
\hline Concentration Difficulties & $0-4$ & 1.21 & 0.82 & 1.25 & 0.90 & 0.91 & 0.76 \\
\hline Lack of Energy & $0-4$ & 1.9 & 0.76 & 1.37 & 1.01 & 1.08 & 0.76 \\
\hline Eating Habits & $0-2$ & 0.91 & 0.65 & 0.5 & 0.73 & 0.74 & 0.65 \\
\hline Sleeping Habits & $0-2$ & 0.85 & 0.80 & 0.8 & 0.66 & 0.91 & 0.74 \\
\hline Overwhelmed & $0-4$ & 0.4 & 0.73 & 1.27 & 0.89 & 1.08 & 0.8 \\
\hline Physical Symptoms & $0-4$ & 1.08 & 0.82 & 1.37 & 0.82 & 1 & 0.76 \\
\hline
\end{tabular}

Table 1 - Scores on the PMTS Scale across all age groups

demographic data, all the three age groups were well matched on the average age of menarche, number of children and regularity of the menstrual cycle.

Table 1 illustrates the mean scores on the PMTS and all it's items in the three age groups. The maximum mean PMTS score $17.6 \pm 6.46$ was found in age group 35-45 years. Depressed mood, affective lability, irritability and impaired concentration were symptoms that had higher scores across the age groups.

Table 2 shows the severity of Premenstrual symptoms in the age groups graded as minimal (0-10), mild (11$20)$, moderate (21-30) and severe (31-40). None of the participants reported minimal symptoms. Most participants had mild symptoms in both the groups $(\mathrm{p}=0.0019)$.

Spearman correlation analysis between total scores of PMTS and that of MAQ for a particular age group showed a negative, linear and significant. The correlation constant of the 2 variables in age group 25-35years is $0.68(-0.761$ to -0.588$)$, that of age group $35-45$ years is $0.788(-0.842$ to -0.718$)$ and that in age group above 45 years is -0.779 ( -0835 to -0.707$)$.

\begin{tabular}{|c|c|c|c|}
\hline Severity Scores on PMTS & 25-35 years & $\mathbf{3 5 - 4 5}$ years & > 45 years \\
\hline Mild (11-20) & 124 & 103 & 130 \\
\hline Moderate (21-30) & 21 & 37 & 14 \\
\hline Severe (31-40) & 5 & 10 & 6 \\
\hline \multicolumn{2}{|r|}{$\mathrm{X}^{2}=16.9615, \mathrm{p}=0.0019$ (significant) } \\
\hline
\end{tabular}

Table 2 - Severity of PMTS symptoms across the age groups

\begin{tabular}{|c|c|c|}
\hline \multirow{2}{*}{ Age Group } & \multicolumn{2}{|c|}{ Correlation between PMTS and MAQ } \\
& scores \\
\cline { 2 - 3 } & r value & Confidence Interval \\
\hline $25-35$ years & -0.68 & -0.835 to -0.707 \\
\hline $35-45$ years & -0.788 & -0.842 to -0.718 \\
\hline$>45$ years & -0.779 & -0.835 to -0.707 \\
\hline
\end{tabular}

Table 3 - Correlation between PMTS Scores and MAQS

\section{DISCUSSION}

This study was undertaken in order to determine the relationship between the severity of PMS symptoms and menstrual attitudes. In this study, there was a negative significant correlation between the following two 
variables of MAQ. In keeping with this study, other researchers have stated that negative menstrual attitudes in nursing students were associated with the severity of PMS [19] and another study reported that PMSS scores were significantly higher in those considering the menstruation a incapacitating event [20]. It is well known that positive and negative attitudes towards menstruation have an impact on women's perceptions and complains about physiological and psychological symptoms in the menstrual period [21]. However, one must interpret with caution as there a limited number of studies examining the relationship of menstrual attitudes with intensity of PMS symptoms experienced by the women [22]. In addition, PMS symptoms have a psychological impact on the women's perception towards the menstrual changes and vice versa. There is a need for future studies to focus on how menstrual attitude affects PMS symptoms. As the severity of premenstrual and menstrual symptoms in women increase, negative attitudes towards menstruation may increase [23]. This could be used in psychoeducational programs for women on menstruation and PMS. The current study has some limitations. Many confounding factors that might influence the intensity of premenstrual symptoms were not considered. The sample size was limited and restricted to nurses just from two centres. Further studies in larger and varied samples are recommended.

The severity of PMS symptoms was be correlated to negative menstrual attitudes in this study. Active intervention directed towards these attitudes and PMS would improve performance at work and also reduce distress in the participants. The study findings can be used in planning educational interventions aimed at coping with PMS symptoms and PMS. Further studies in this direction are warranted.

\section{REFERENCES}

1. Lu ZY. The relationship between menstrual attitudes and menstrual symptoms among Taiwanese women. J Adv Nurs 2001;33(5):621-8.

2. Erbil N, Karaca A, Kırış T. Investigation of premenstrual syndrome and contributing factors among university students. Turk J Med Sci 2010;40(4):565-73.

3. Selçuk KT, Avcı D, Yılmaz F. The prevalence of premenstrual syndrome among nursing students and affecting factors. J Psychiatr Nurs 2014;5(2):98-103.

4. Ozisik Karaman HI, Tanriverdi G, Degirmenci Y. Subjective sleep quality in premenstrual syndrome. Gynecol Endocrinol 2012;28(8):661-4.

5. Dickerson LM, Mazyck PJ, Hunter MH. Premenstrual syndrome. Amer Fam Physician 2003;67(8):1743-52.

6. Yonkers KA, O'Brien PS, Eriksson E. Premenstrual syndrome. Lancet 2008;371(9619):1200-10.

7. Baker FC, Kahan TL, Trinder J, Colrain IM. Sleep quality and the sleep electroencephalogram in women with severe premenstrual syndrome. Sleep. 2007;30(10):1283-91.

8. Biggs WS, Demuth RH. Premenstrual syndrome and premenstrual dysphoric disorder. Amer Fam Physician 2011;84(8):918-26.

9. Nisar N, Zehra N, Haider G, Munir AA, Sohoo NA. Frequency, intensity and impact of premenstrual syndrome in medical students. J Coll Physicians Surg Pak 2008;18(8):481-4.

10. Lete I, Dueñas JL, Serrano I, Doval JL, Martínez-Salmeán J, Coll C, Pérez-Campos E, Arbat A. Attitudes of Spanish women toward premenstrual symptoms, premenstrual syndrome and premenstrual dysphoric disorder: results of a nationwide survey. Eur J Obstetr Gynecol Reprod Biol 2011;159(1):115-8.

11. Halbreich U, Backstrom T, Eriksson E, O'brien S, Calil H, Ceskova E, Dennerstein L, Douki S, Freeman E, Genazzani A, Heuser I. Clinical diagnostic criteria for premenstrual syndrome and guidelines for their quantification for research studies. Gynecol Endocrinol 2007;23(3):123-30.

12. Braverman PK. Premenstrual syndrome and premenstrual dysphoric disorder. J Pediatr Adolesc Gynaecol 2007;20(1):3-12.

13. Tschudin S, Bertea PC, Zemp E. Prevalence and predictors of premenstrual syndrome and premenstrual dysphoric disorder in a population-based sample. Arch Wom Ment Health 2010;13(6):485-94.

14. Hamaideh SH, Al- Ashram SA, Al- Modallal H. Premenstrual syndrome and premenstrual dysphoric disorder among Jordanian women. J Psych Ment Health Nurs 2014;21(1):60-8.

15. Kim HO, Lim SW, Woo HY, Kim KH. Premenstrual syndrome and dysmenorrhea in Korean adolescent girls. Korean J Obstetr Gynecol 2008;51(11):1322-9.

16. Vichnin M, Freeman EW, Lin H, Hillman J, Bui S. Premenstrual syndrome (PMS) in adolescents: severity and impairment. J Pediatr Adolesc Gynaecol 2006;19(6):397-402.

17. Steiner M, Peer M, Macdougall M, Haskett R. The premenstrual tension syndrome rating scales: an updated version. J Affect Disord 2011;135(1-3):82-8.

18. Firat MZ, Kulakaç Ö, Öncel S, Akcan A. Menstrual attitude questionnaire: confirmatory and exploratory factor analysis with Turkish samples. J Adv Nurs 2009;65(3):652-62.

19. Song JE, Chae HJ, Jang WH, Park YH, Lee KE, Lee SH, Jang HA, Jeon JH, Jung MS. The relationship between life style, menstrual attitude and premenstrual syndrome in nursing students. Korean J Wom Health Nurs 2013;19(2):119-28. 
20. Guvenc G, Kilic A, Akyuz A, Ustunsoz A. Premenstrual syndrome and attitudes toward menstruation in a sample of nursing students. J Psychosom Obstetr Gynecol 2012;33(3):106-11.

21. Hwang JH, Sung MH. Impacts of menstrual attitudes, premenstrual syndrome and stress on burnout among clinical nurses. Korean J Wom Health Nurs 2016;22(4):233-40.

22. Wong LP. Attitudes toward menstruation, menstrual-related symptoms, and premenstrual syndrome among adolescent girls: a rural school-based survey. Wom Health 2011;51(4):340-64.

23. Campagne DM, Campagne G. The premenstrual syndrome revisited. European J Obstetr Gynecol Reprod Biol 2007;130(1):4-17.

\section{Acknowledgements - Nil \\ Conflict of Interest - Nil \\ Funding - Nil}

